\title{
Self-other and third-person categorization in normal and autistic children
}

\section{Guido Peeters, ${ }^{1}$ Goele Grobben, ${ }^{1}$ Ann Hendrickx, ${ }^{2}$ Steven Van den Eede ${ }^{1}$ and Karen Verlinden ${ }^{1}$}

1. Department of Psychology, Katholieke Universiteit Leuven, Belgium

2. Sancta Maria Psychiatric Hospital, Sint-Truiden, Belgium

\begin{abstract}
Social information processing has been found to vary as a function of whether perceivers categorize individuals in terms of self and other (SO-categorization) or using categories associated with the third pronominal person (3P-categorization). Normal children aged 3-8, autistic children aged 5-9 and adult students were presented with decision tasks that enabled us to assess the use of $S O$-and $3 P$-categorizations. A breakthrough of the SO-categorization was observed at age 5. The hypothesis that $3 P$-categorization precedes SO-categorization was strongly disconfirmed, only adults showing consistent $3 P$-categorization. Although previous research suggested a strong association between SO-categorization and 'I-Thou' related social understanding, performances of autistic children suggested that impaired understanding of mental life does not detract from the ability to use SO-categorization.
\end{abstract}

\section{Introduction}

Imagine a picture of you, the reader, and one of me, the author, next to each other on the table. I point to my picture and tap it with my finger. Then I ask you to do the same as I just did. Which picture would you tap? The answer depends on whether you categorize the pictures as pictures of 'self' and 'Other' (SO-categorization) or as pictures of individuals conceived of in accordance with the third pronominal person (3P-categorization). For instance, using the SO-categorization, the pictures may be categorized as my picture and your picture; using the $3 \mathrm{P}$-categorization they may be categorized as a picture of him who's the author and a picture of her who's the reader. Hence using SO-categorization, you may observe that I tapped my own picture. Acting likewise you too may tap your own picture which is the reader's. Alternatively, using the 3P-categorization, you may observe that I tapped the author's picture, and acting likewise you too may tap the author's picture.

The duality of SO- and 3P-categorization has been found highly relevant for social perception and cognition and for the processing of certain ambiguities in verbal communication (for recent reviews, see Hendrickx \& Peeters, 1997; Peeters \& Hendrickx, 1998). One persist- ent research outcome is that perceivers seem biased to process social information using the SO-categorization rather than the 3P-categorization. Particularly, impressions of personality seem inexorably attached to the SO-categorization. For instance, Peeters (1991, Experiment 2) presented students with situations such as 'A likes B because B is punctual and B likes A because A is sensitive; A and B do not like themselves'. The students' task was to provide similarity vs. difference ratings of A and B's personalities. If they used the 3P-categorization, they might reason that $\mathrm{A}$ and $\mathrm{B}$ have different personalities: A could be a sensitive and slovenly person who likes punctual people and is worried about their own lack of punctuality; B then would be a rather insensitive and punctual person who likes sensitive people and is worried about their own lack of sensitivity. However, the way the students proceeded was different. They used the SO-categorization and concluded that $\mathrm{A}$ and B's personalities were alike in that both A and B liked others but were embroiled with themselves. Moreover, (dis)liking relations with self and other were found to be strong cues for selective trait attributions that reflected the same dimensional structure as other investigators had obtained for implicit personality theory (Peeters, 1983).

\footnotetext{
Address for correspondence: Guido Peeters, LESP, Tiensestraat, 102, B-3000 Leuven, Belgium; e-mail: guido.peeters@psy.kuleuven.ac.be Ann Hendrickx, is now at the Welfare, Public Health and Culture Department of the Flemish government, Brussels, Belgium. The collaboration of Goele Grobben, Steven Van den Eede, and Karen Verlinden formed part of the preparation of their dissertations submitted to obtain the degree of Licentiate of Psychology.
} 
Perceivers use the 3P-categorization only in particular conditions. For instance, it is used when perceivers use extant interpretive concepts that have built in the $3 \mathrm{P}$ categorization - e.g. certain common concepts of justice (Peeters, 1987) and psychoanalytic concepts (Peeters \& De Wit, 1995). The 3P-categorization is also used in natural sciences (Peeters \& Hendrickx, 2002) and in the processing of information about impersonal features of humans. For instance, given the information that $\mathrm{A}$ thinks he is taller than B, and B thinks the same, perceivers infer, consistent with the 3P-categorization, that $\mathrm{B}$ agrees that $\mathrm{A}$ is the taller one. However, adding a minimal suggestion of a social relationship suffices to produce significant shifts towards SO-categorization. For instance if $\mathrm{A}$ and $\mathrm{B}$ are described as 'friends' or 'colleagues', perceivers are more inclined to infer that B thinks that she (B) is the taller one (Hendrickx \& Peeters, 1997).

The present study was designed to map the development of SO- and 3P-categorization in children. Our hypothesis was that the use of 3P-categorization would precede that of SO-categorization. This hypothesis was based on the following considerations.

In a previous study (Peeters, 1989), it was demonstrated that the use of SO-categorization reflects thinking in terms of the correlative first and second person or 'I-Thou relatedness' (Buber, 1970). In linguistic and social-cognitive development, speaking and thinking in the third person would emerge first and indicate that the children deal with themselves as physical objects. The ability to handle the 'I-Thou' relatedness would emerge later when the children are able to deal with themselves as persons among other persons (Fernyhough, 1997; Russell, 1996). It is not clear at which age this ability emerges. Many studies on children's theory of mind suggest later ages than studies based on observation of children's talk (Flavell, 1999; Hala \& Carpendale, 1997). Nevertheless, assuming the developmental precedence of third person thinking to I-Thou thinking, it makes sense to expect that the younger the children are, the more they are inclined to 3P-categorization even if they might have acquired the ability of SO-categorization.

In addition, it was expected that the breakthrough of SO-categorization would hold off if the subject's theory of mind is impaired as it would be in autistic children (Hala \& Carpendale, 1997).

\section{Design}

SO- and 3P-categorization was assessed using a series of playful tasks in the course of which the child made nine dichotomous choices each of which discriminated between the SO- and 3P-categorization. There were no wrong responses: the SO- and 3P-categorizations were equally plausible and logically correct. From the first task on, responses were reinforced by the experimenter by informing the respondent that his/her choice was right. According to the 'Win-Stay' principle respondents should persist using the same categorization.

The tests were administered to normal children representing ages $3-8$, adult psychology students and autistic children aged 5-9.

\section{Method}

\section{Participants}

Normal children

With parents' permission, 126 children were individually tested at school. They belonged to three nursery school grades and the first three primary school grades that constituted six groups of ages $3,4, \ldots 8$. All children had fully reached the given age at least two months beforehand.

\section{Autistic children}

Forty-four children (aged between 5 and 9, $M e=7$ ) attending special classes for children with autism in five educational institutes were tested at school.

\section{Adults}

Twenty-six psychology freshmen (aged about 18) volunteered to help with the preparation of a developmental psychological experiment by acting as participants.

\section{Procedure}

The child was welcomed by the experimenter and her assistant (female graduate students). The latter was dressed as a princess. The experimenter told a story of a princess who had to take care of a treasure kept behind five locked doors. Visitors got access to the treasure if they could successfully play five games. If a visitor was successful the princess rang a hand-bell, which meant that one of the doors was opened and the visitor could play the next game.

The experimenter invited the child to play the games with her. The games required the child to choose nine times between alternatives reflecting respectively the SOand 3P-categorization. These choices are numbered $\mathrm{Cl}$, $\mathrm{C} 2, \ldots \mathrm{C} 9$. At the end of each game the princess rang the bell rewarding both SO- and 3P-choices, and the 
experimenter said: 'Well done! The princess opens one of the doors and we go to the next game.'

The princess noted the children's choices and invited them to comment on their choices if they wanted. It took about 10 minutes to reach the treasure: a box with medals, one of which was offered to the child.

\section{Games}

\section{Photo game}

Two passport photographs, one of the child and one of the experimenter, were displayed next to each other on a table. The experimenter made sure that the child could overlook the scene and was aware of the identity of the photographed persons. Then she said: 'I am going to do something and then you have to do the same.' She walked to the table, tapped twice just below her own photograph, and said: 'Now you do the same.' (C1: tapping their own photograph $=S O$, tapping the experimenter's photograph $=3 P$.)

\section{Tunnel game}

A red and a blue cloth were spread on the floor. The experimenter said: 'These are two tunnels. What's their color? ...' Then she showed two cards on strings: 'Here are a red card and a blue card. Which card do you take?' The experimenter hung the chosen card on the child's neck, the other card on her own neck and said: 'I will crawl through the tunnel. Watch well so you can later do the same.' The experimenter went to the cloth of same color as her card and passed crawling under the cloth. Then she said: 'Now you do the same!' (C2: passing under their own color $=S O$, under the experimenter's color $=3 P$.)

\section{Ball game}

The experimenter pointed to a table with drawing-paper and colored pencils: 'We are going to draw pictures. What do you want to draw? I will draw it too ...' When the drawings were finished, she continued: 'Now we hang the drawings on chairs. So this chair becomes a goal post with your drawing, and that chair becomes one with my drawing.' She tagged the drawings on adjacent chairs and says: 'Look at what I do, so you can do the same later.' Experimenter and child stood in front of the chairs facing the two drawings whereby the experimenter takes care that neither is posted exactly in front of their own drawing. The experimenter took the ball, threw it under the chair with her drawing and said: 'Now you can do the same.' (C3: ball thrown under their own drawing $=S O$, under the experimenter's drawing $=3 P$.)

\section{Letter-box game}

The experimenter showed two badges (an emblematic house, and an emblematic flower). The child chose one, got it pinned up, and the experimenter took the other. Several envelopes were within reach: some white ones, some marked with the house, and some marked with the flower. There were also two adjacent letter-boxes marked respectively with the house and the flower. The experimenter said: 'We're going to mail letters. Look at what I do.' She put a white envelope in the box with the same emblem as her badge. Then she said: 'Now you do the same.' (C4: envelope put in box with own emblem $=\mathrm{SO}$, in box with experimenter's emblem $=3 P$.) The princess rang the bell and the experimenter took an envelope with the emblem of her badge, put it in the box with the same emblem, and said: 'Now you do the same!' (C5: child takes envelope with own emblem $=S O$, with experimenter's emblem $=3 P$. C6: child puts envelope in box with own emblem $=S O$, in box with experimenter's emblem $=$ $3 P$.) The princess rang and the experimenter again took an envelope with her own emblem but put it in the box with the child's emblem, and said: 'Now you do the same.' (C7: Child takes envelope with own emblem $=S O$, with experimenter's emblem $=3 P$. C8: Child puts envelope in box with experimenter's emblem $=S O$, in box with own emblem $=3 P$.)

\section{Puppet game}

The experimenter tagged the child's and her own pictures on the faces of puppets. She said: 'Here are two puppets, one has your head and one has mine. Again I will do something and then you do the same.' She manipulated the puppet with her picture and made it look behind a screen while saying: 'I look for where the treasure might be. Oh! I've found it. Now you do the same.' (C9: child using the puppet with the child's picture $=S O$, using that with the experimenter's $=3 P$.)

\section{Differences between group treatments}

The frame-story of the princess was not used when testing adults, who found it hilarious, or for autistic children, for whom it would have complicated the situation too much. Instead the participants were simply asked to pass through a series of game-tasks. The autistic group was handled by different experimenters, a male graduate student and a caretaker who was familiar to the children. The caretaker administered the tests while the student was merely present supervising the session. Some details that might frighten the children or lead to dubious responses were adjusted: bell ringing was omitted, 
selected photographs were seized and turned rather than just tapped, and in the tunnel game walking over a cloth was substituted for crawling under it.

\section{Results}

\section{Data analysis}

Each respondent made nine choices each of which fitted either the SO- or the 3P-categorization. A respondent's number of $\mathrm{SO}$ consistent choices constituted a score with a potential range from 0 (9 3P consistent choices) to 9 (9 SO consistent choices). Mere random responding would approach a normal distribution (Mean $=4.5$ ). With choices being rewarded, respondents should stick to the categorization they started with. Thus scores close to chance expectation would not indicate that respondents switched between categorizations but that they made random choices or used criteria that were unrelated to SO- and 3P-categorizations. ${ }^{1}$ It follows that only extreme scores might be diagnostic for the use of SOand 3P-categorizations. At this point the question arises how extreme scores should be in order to classify participants as $\mathrm{SO}$ and $3 \mathrm{P}$ consistent respondents. In the paper presented at the 'Decolage 2001' conference (Peeters, Grobben, Hendrickx, Van den Eede \& Verlinden, 2001), a quite conservative criterion was used of at least 8 consistent choices, which means: scores lower than 2 or higher than 7 (chance expectation: $p<.04$ ) Unfortunately, only $47 \%$ of the participants reached that criterion. Hence, in the present paper we use a more relaxed criterion of 7 consistent choices (scores lower than 3 or higher than 6). In this way $70 \%$ of the participants could be classified as consistent respondents, but the probability of reaching the criterion by chance increased to $p<.18$ ( $<.09$ for SO consistency, and $<.09$ for $3 \mathrm{P}$ consistency).

Frequencies of SO consistent, 3P consistent and inconsistent respondents were transformed in proportions presented in Table 1. Unless indicated otherwise, statistical significance was tested using nonparametric binomial and Fisher tests.

\footnotetext{
${ }^{1}$ In their comments children sometimes mentioned similar unrelated criteria. For instance, instead of saying that they took a particular tunnel because it had the color of their own card $(\mathrm{SO})$ or because it was the tunnel taken by the experimenter (3P), they might say that they took the tunnel because they liked its color. However, it has been found that even advanced psychology students are often unable to report correctly the SO- or 3P-categorizations they use, and formulate rationales that in point of fact cannot account for their test responses (Peeters, 1991).
}

Table 1 Proportions of consistent and inconsistent participants ${ }^{\mathrm{a}}$ expected by chance and obtained in groups of children aged $3-8$, adults and autistic children

\begin{tabular}{|c|c|c|c|c|c|c|c|c|c|}
\hline & \multirow{2}{*}{$\begin{array}{l}\text { Expect. } \\
\text { by } \\
\text { chance }\end{array}$} & \multicolumn{8}{|c|}{ Participant groups } \\
\hline & & 3 & 4 & 5 & 6 & 7 & 8 & Adult & Autistic \\
\hline SO Consist. & .09 & .24 & .33 & .88 & .83 & .89 & .75 & .46 & .64 \\
\hline Inconsist. & .82 & .76 & .63 & .06 & .17 & .11 & .25 & .23 & .25 \\
\hline 3P Consist. & .09 & .00 & .04 & .06 & .00 & .00 & .00 & .31 & .11 \\
\hline$N$ & & 17 & 24 & 16 & 35 & 18 & 16 & 26 & 44 \\
\hline
\end{tabular}

Note: a A participant is categorized as consistent if (s)he produced at least 7 out of 9 responses consistent with the same categorization, being either the SO categorization (SO consistent participants scoring above 6) or the $3 \mathrm{P}$ categorization (3P consistent participants scoring below 3 ).

\section{Inconsistent (versus consistent) responding}

A first analysis focused exclusively on proportions of inconsistent respondents, which are respondents that did not meet the criterion of 7 consistent choices. Table 1 shows that in general the inconsistent response rate was lower than chance, although the chance level (.82) was approached by the groups of ages 3 and 4 . Actually the difference between the proportion of inconsistent respondents pooled across ages 3-4 and the proportion expected by chance was only marginally significant, Chisquare $(1, N=41)=5.22, .01<p<.05$. However, from age 5 on, it dropped dramatically to a low level that extended to the adult and autistic groups. Actually, the only significant difference between successive ages was observed between ages 4 and $5(p<.001)$. Adults differed significantly from age groups $3(p<.005)$ and 4 $(p<.01)$ but not from any other group. Also autistic children differed significantly from age groups $3(p<.0005)$ and $4(p<.005)$, but not from their normal peers (the pooled group of ages 5-8). Apparently consistent categorization was rather exceptional in the lowest age groups but increased rapidly at age 5 to a relatively high and stable level that marked not only normal children and adults, but autistic children as well.

\section{SO- (versus 3P-) categorization in consistent respondents}

This analysis was restricted to participants who were classified as consistent respondents. As shown in Table 1 , the SO-categorization was overwhelmingly dominant in all groups. Only the adult group stood out with a proportion of 3P-categorizations that differed significantly from the combined normal children groups $(p<.001)$. Most surprisingly, the SO dominance marked also the autistic children who did not differ significantly from the adults and hardly at all from their normal peers (age 
Table 2 Proportions ${ }^{\mathrm{a}}$ of SO consistent choices per choice item

\begin{tabular}{|c|c|c|c|c|c|c|c|c|c|c|c|}
\hline \multirow[t]{2}{*}{ Group } & \multirow[t]{2}{*}{$N$} & \multicolumn{9}{|c|}{ Choice items } & \multirow{2}{*}{$\begin{array}{l}\text { Cronbach } \\
\text { alpha }^{\mathrm{b}}\end{array}$} \\
\hline & & $\mathrm{C} 1$ & $\mathrm{C} 2$ & $\mathrm{C} 3$ & $\mathrm{C} 4$ & $\mathrm{C} 5$ & C6 & $\mathrm{C} 7$ & $\mathrm{C} 8$ & $\mathrm{C} 9$ & \\
\hline $3-4$ & 41 & $.28 *$ & .49 & .51 & $.90 * *$ & $.88^{* *}$ & $.83 * *$ & .61 & .37 & $1.00^{* *}$ & .31 \\
\hline $5-8$ & 85 & .47 & $.82 * *$ & $.73 * *$ & $.92 * *$ & $.93^{* *}$ & $.94 * *$ & $.88^{* *}$ & $.85^{* *}$ & $.99 * *$ & .58 \\
\hline Adult & 26 & .46 & .65 & .35 & .54 & .62 & .62 & .54 & .46 & $.81 * *$ & .86 \\
\hline Autist. & 44 & .50 & $.72 *$ & .43 & $.75^{*}$ & $.80^{* *}$ & $.80 * *$ & $.77 * *$ & .59 & $.86^{* *}$ & .74 \\
\hline
\end{tabular}

$* p<.01 * * p<.001$

Notes: ${ }^{a}$ Notice that subtracting these proportions from 1.00 yields the proportions of $3 \mathrm{P}$ consistent choices.

${ }^{\mathrm{b}}$ Computed on the basis of items $\mathrm{C} 1-\mathrm{C} 8$, C9 lacking sufficient variability.

$5-8)(.01<p<.05)$. This marginally significant difference could indicate that autistic children may be a little more inclined to 3P-categorization (less to SO-categorization) than their normal peers are. However, it does not detract from the evidence that even autistic children produce predominantly SO consistent responses.

\section{Comparison with results from a conservative analysis}

The outcomes of the present analysis are in almost perfect agreement with those obtained by Peeters et al. (2001) using the conservative criterion of minimally 8 consistent choices. The only noteworthy difference is that the marginally significant tendency to have more 3P consistency in autistic than in normal children did not show up in the conservative analysis. Hence it would be unwarranted to conclude that autistic children are really more inclined to 3P-categorization - or less to SOcategorization - than normal children are. Moreover, the difference may be due to the procedural differences described in the method section. Actually, the experimenter who worked with the autistic children also worked with 16 normal children of age 4 . The results did not differ significantly from those obtained from the children of age 4 who produced the outcomes presented in Table 1. Nevertheless, the children treated in the way of the autistic children produced $10 \%$ more $3 \mathrm{P}$ consistent (10\% less SO consistent) responses. Although this difference is not significant, it casts further doubt on the suggestion that autistic children would use more 3Pcategorization than normal children.

\section{SO and $3 P$ consistent responses across choices}

Participants passed through nine successive choice items C1-C9 each of which allowed for either an SO consistent or a 3P consistent choice. Proportions of SO consistent choices are presented in Table 2. Asterisked proportions deviate significantly from chance (.50). No marginally significant deviations $(.01<p<.05)$ were obtained.

With choices being rewarded, participants could be expected to persist in using the categorization they started with at $\mathrm{C} 1$. This should have resulted in more or less constant proportions across choices combined with a high Cronbach alpha value. Only the adults produced that pattern. Apparently they started choosing randomly between $\mathrm{SO}$ and $3 \mathrm{P}$ consistent alternatives and they tended to continue using the same categorization as in previous choices. Also the normal children of ages 5-8 and the autistic children produced nearly random proportions at $\mathrm{C} 1$, but from $\mathrm{C} 2$ on, they showed a significant preference for $\mathrm{SO}$ consistent choices. Two proportions in the autistic group (for $\mathrm{C} 3$ and $\mathrm{C} 8$ ) that were not significantly higher than chance hardly detracted from that pattern. Apparently, in spite of the reinforcement provided by the experimenter, $3 \mathrm{P}$ consistent choices tended not to be repeated but gave way to SO consistent choices. This suggests not only that respondents were biased to use SO-categorization, but also that the initial 3P consistent choices were not really based on the use of 3P-categorization.

Finally, the pattern produced by the normal children of ages 3-4 is remarkable. A significant majority of the children started with a $3 \mathrm{P}$ consistent choice, but at $\mathrm{C} 2$ and $\mathrm{C} 3$ they dropped to the level expected by chance. Although choices were rewarded, tests of independence failed to demonstrate a significant relationship between these successive choices. Considering also the low alpha coefficient, this suggests that not only $3 \mathrm{P}$ consistent choices, but also SO consistent choices were not produced by using the corresponding SO- and 3P-categorizations. At $\mathrm{C} 4$, however, $\mathrm{SO}$ consistent choices rose to a very high level. At C7 and C8 they fell, but then rose again to an absolute maximum at C9. This irregular response profile, and the low alpha coefficient, suggest that choices may reflect irrelevant item effects rather than the use of SO- and 3P-categorization. This interpretation is further supported by the observation that the same irregular 
profile transpires in the other groups in which the presumed effects of SO- and 3P-categorization seem superimposed on the item effects. ${ }^{2}$

\section{Discussion and perspectives}

The hypothesis that the use of 3P-categorization would precede that of SO-categorization in development is disconfirmed. Consistent SO-categorization was observed across all age groups - with a breakthrough at age 5 but only adults yielded convincing evidence of consistent 3P-categorization. It is noteworthy that in their comments, adults often justified 3P consistent choices arguing that they did 'exactly' the same as the experimenter did. Although there were no logical grounds to qualify SO-categorization as less 'exact' than 3Pcategorization, 'exactness' was never mentioned to justify SO-categorization. Presumably using the term 'exactly', participants communicated that they adopted the objectivistic scientific-like attitude that in the introductory section was connected with 3P-categorization. Apparently, effective 3P-categorization belongs to a more advanced developmental level than that reached by young children who often converse using third-person terms, such as their own and addressee's names, rather than the pronouns I and you. Hence, future research may investigate whether effective 3P-categorization belongs to an advanced stage of formal thinking rather than to an early stage of preoperational thinking.

Research reviewed in the introductory section suggested a strong association between SO-categorization and the perception of self and other as 'I-Thou related' personal beings. The ability to engage in 'I-Thou' relationships and the related ability of mental understanding are seriously impaired in autistic people. Nevertheless, we found hardly any difference between autistic and other children's inclinations to use SO-categorization. Apparently SO-categorization involves an impersonal component that enables correct use of SO-categorization without having it implemented with the rich existential content associated with 'I-Thou' relatedness. The exact nature of this component may be explored in the light of previous studies dealing with connections between social and nonsocial aspects of behavior (e.g. Feffer, 1970; Neisser, 1993a; Selman, 1976). In particular, the study of the relationship between social and spatial information processing, whether it be in the Piagetian approach of Feffer or the Gibsonian approach of Neisser, seems promising. For instance, SO-categorization may be related to

\footnotetext{
${ }^{2}$ Product moment correlations between the profiles in Table 2 range between .62 and .87 .
}

the 'ecological self' (Neisser, 1993b) that is distinguished from the 'I-Thou' related 'social self', to which it may be a necessary, though not sufficient, prerequisite (Loveland, 1984, 1993).

A final point concerns the outstanding item effects. The present data may not be suited to explain why some items elicited much more SO consistent choices than others. An exception may be the contrast between the first and the last item. Both required the participant to choose between their own and the experimenter's picture. The nearly random response pattern at $\mathrm{C} 1$, even in age groups that were clearly biased to SO consistent responding, may be due to the initial insecurity experienced by a child confronted with an unfamiliar situation. However, why was the utmost amount of SO consistent responding obtained at $\mathrm{C} 9$ where participants chose between the same pictures as at $\mathrm{C} 1$ ? Order effects and response generalizations from previous choices may not suffice to explain why only at $\mathrm{C} 9$ the adult group produced significantly more SO consistent than $3 \mathrm{P}$ consistent choices. In the search for an explanation, one could point to the fact that at $\mathrm{C} 9$ the photographs did not function as passive objects that were only observed and briefly touched, but as active characters in a puppet show. Hence another subject of future research may deal with the possible role of agency as a moderator of SOcategorization.

\section{Acknowledgements}

The authors are greatly indebted to directors, staff and pupils of the following schools and institutes for their precious cooperation: Auticant (Borgerhout), Dennenhof (Schilde), Gemeentelijke Kleuterschool (Zoersel), Jonghelinckshof (Antwerpen), Kids (Hasselt), Paridaensinstituut (Leuven), Onze-Lieve-Vrouw-van-Lourdescollege (Edegem), St. Jozefsinstituut (Leuven), St. Rafaël Instituut (Brecht).

\section{References}

Buber, M. (1970). I and thou. Edinburgh: Clark.

Feffer, M. (1970). Developmental analysis of interpersonal behavior. Psychological Review, 77, 197-214.

Fernyhough, N. (1997). Vygotsky's sociocultural approach: theoretical issues and implications for current research. In S. Hala (Ed.), The development of social cognition (pp. 65-94). Hove: Psychology Press.

Flavell, J.H. (1999). Cognitive development: children's knowledge about the mind. Annual Review of Psychology, 50, 21-45.

Hala, S., \& Carpendale, J. (1997). All in the mind: children's understanding of mental life. In S. Hala (Ed.), The

(C) Blackwell Publishing Ltd. 2003 
development of social cognition (pp. 189-239). Hove: Psychology Press.

Hendrickx, A., \& Peeters, G. (1997). A psycholinguistic paradigm of dual information processing in social cognition. Psychologica Belgica, 37, 205-218.

Loveland, K.A. (1984). Learning about points of view: spatial perspective and the acquisition of I/you. Child Language, Il, 535-556.

Loveland, K.A. (1993). Autism, affordances, and the self. In U. Neisser (Ed.), The perceived self. Ecological and interpersonal sources of self-knowledge (pp. 237-253). Cambridge: Cambridge University Press.

Neisser, U. (Ed.) (1993a). The perceived self. Ecological and interpersonal sources of self-knowledge. Cambridge: Cambridge University Press.

Neisser, U. (1993b). The self perceived. In U. Neisser (Ed.), The perceived self. Ecological and interpersonal sources of selfknowledge (pp. 3-21). Cambridge: Cambridge University Press.

Peeters, G. (1983). Relational and informational patterns in social cognition. In W. Doise \& S. Moscovici (Eds.), Current issues in European social psychology. Vol. 1 (pp. 201-237). Cambridge: Cambridge University Press.

Peeters, G. (1987). The Benny Hill effect: switching cognitive programmes underlying subjective estimations of the outcomes of bargains concerning distributions of rewards. European Journal of Social Psychology, 17, 465-481.

Peeters, G. (1989). Person and non-person as basic concepts underlying alternative discourses about reality. An analysis based on the social-psychological relation-pattern model and Greimas' semiotic square. Ultimate Reality and Meaning. Interdisciplinary Studies in the Philosophy of Understanding, 12, 113-132.

Peeters, G. (1991). Relational information processing and the implicit personality concept. Cahiers de Psychologie Cognitive - European Bulletin of Cognitive Psychology, 11, 259-278.

Peeters, G., \& De Wit, R. (1995). Self-other and third-person anchored modes of thinking in psychological expertise: cognitive concomitants of behaviourist, client-centred, and psychoanalytic concepts. International Journal of Psychology, 30, 317-328.

Peeters, G., Grobben, G., Hendrickx, A., Van den Eede, S., \& Verlinden, K. (2001). The development of self-other and third-person categorization in social perception and cognition: an empirical study. Decolage 2001: Proceedings of the 2nd Bisontine Conference for the Conceptual and Linguistic Development of the Child Aged from 1 to 6 Years. (CD-ROM). Besançon: Laboratory of Psychology EA3188, University of Franche-Comté.

Peeters, G., \& Hendrickx, A. (1998). Alternative cognitive programs underlying self-other and other-other comparisons: an illustration with gender categorization. Revue Internationale de Psychologie Sociale - International Review of Social Psychology, 11, 97-113.

Peeters, G., \& Hendrickx, A. (2002). The similarity between the perception and interpretation of information in a profane and a religious context. The International Journal for the Psychology of Religion, 12, 41-52.

Russell, J. (1996). Agency: Its role in mental development. Hove, UK: Lawrence Erlbaum Associates.

Selman, R.L. (1976). Social-cognitive understanding: a guide to educational and clinical practice. In T. Lickona (Ed.), Moral development and behavior: Theory, research and social issues (pp. 299-316). New York: Holt, Rinehart and Winston.

Received: 8 August 2001

Accepted: 21 December 2001 